\title{
El delito de acoso sexual basado en la orientación sexual como manifestación de la discriminación
}

\section{The crime of sexual harassment based on sexual orientation as a manifestation of discrimination}

\author{
Claudia Lucía Castro Barnechea ${ }^{[*]}$ \\ Pedro Junior Calvay Torres ${ }^{[* *]}$
}

\begin{abstract}
Resumen: el reciente Decreto Legislativo 1410 incorpora cuatro delitos al Código Penal peruano, conductas que deberían haber estado sancionadas desde hace mucho tiempo pero que han formado parte de las manifestaciones de violencia que se normalizan en nuestra sociedad. El acoso, acoso sexual, chantaje sexual y la difusión de imágenes con contenido sexual han sido conductas comunes por mucho tiempo, generando un contexto de constante violencia contra ciertos grupos en una situación de especial vulnerabilidad. El presente artículo analizará los elementos del delito de acoso sexual descrito en el Decreto Legislativo 1410, así como las posibles implicancias que traerá su criminalización bajo una perspectiva de género.
\end{abstract}

Palabras claves: acoso sexual, orientación sexual, delito.

Abstract: the recent Legislative Decree 1410 incorporates four crimes to the Peruvian Penal Code, these conducts should have been sanctioned a long time ago but they are part of the manifestations of violence normalized in our society. Harassment, sexual harassment, sexual blackmail and the dissemination of images with sexual content have been common behavior for a long time, generating a context of constant violence against certain groups in a situation of special vulnerability. This paper will analyze the elements of the crime of sexual harassment described in Legislative Decree 1410 as well as the possible implications of its criminalization from a gender perspective.

Keywords: sexual harassment,sexual orientation, crime.

[*] Abogada y Magister en Derechos Humanos por la Pontificia Universidad Católica del Perú (PUCP). Abogada en el Área de Litigio Estratégico de PROMSEX. Docente de la Facultad de Derecho de la PUCP y la Universidad Norbert Wiener. Contacto: castro.barnechea@gmail.com

[**] Magister en Derechos Humanos por la PUCP. Coordinador Académico de la Facultad de Derecho de la Universidad Tecnológica del Perú (UTP) y docente en la Facultad de Derecho de la UTP.

Contacto: pedrocal vay@gmail.com 
El reciente Decreto Legislativo 1410 incorpora cuatro delitos al Código Penal peruano, conductas que deberían haber estado sancionadas desde hace mucho tiempo pero que han formado parte de las manifestaciones de violencia que se normalizan en nuestra sociedad. El acoso, acoso sexual, chantaje sexual y la difusión de imágenes con contenido sexual han sido conductas comunes por mucho tiempo, generando un contexto de constante violencia contra ciertos grupos en una situación de especial vulnerabilidad.

Desde las situaciones más cotidianas, se pretende hacer pasar al acoso por una mal entendida galantería, un inocente coqueteo o la broma para amenizar el rato entre amigos. Lamentablemente, la discriminación es buena ocultándose detrás de estereotipos y disimulando la violencia tras la broma o el «piropo» no consentido.

Es el acoso sexual, entonces, uno de los tipos penales más interesantes de analizar, especialmente si se considera quienes son, generalmente, las «víctimas» de este delito o hacia quienes se dirige esta conducta y cómo se configuran los requisitos del tipo penal en esta nueva norma. Para realizar un análisis del acoso sexual como delito se hace necesario considerar el contexto en el que estas conductas se producen y el cambio que ha generado que pase de conducta socialmente aceptada a delito.

Nuestro sistema judicial, en lo referente a casos vinculados a la violencia de género, no ha tenido pronunciamientos que contextualicen la problemática de la violencia sexual en el Perú. Un análisis ausente que muchas veces ha terminado por justificar decisiones controversiales y eminentemente legalistas que han promovido la impunidad de casos que, bajo parámetros de género, hubieran tenido resultados totalmente diferentes.

Es en ese sentido que se abordan a continuación algunas ideas importantes en torno a la reflexión del tipo penal desde una perspectiva de género, aspirando a que este bre- ve aporte devele los primeros problemas que traerá la aplicación del tipo penal de acoso sexual en el Perú.

\section{EL ACOSO SEXUAL COMO FORMA DE VIOLENCIA SEXUAL}

Es evidente que el acoso sexual implica, necesariamente, una afectación a la víctima y, por ende, una serie de secuelas en sus aspectos físicos, psíquicos y emocionales. En ese sentido, el acoso sexual constituye una forma de violencia sexual que ha sido muchas veces ignorada de los grandes análisis sobre violencia, pero que poco a poco ha comenzado a surgir en el imaginario de la sociedad como una clara agresión, una forma directa y normalizada de violencia sexual.

Para la Organización Mundial de la Salud (OMS), la violencia sexual se define como:

todo acto sexual, la tentativa de consumar un acto sexual, los comentarios o insinuaciones sexuales no deseados, o las acciones para comercializar o de cualquier otra manera, en contra de la sexualidad de una persona mediante coerción, por cualquier persona independientemente de la relación de esta con la víctima, en cualquier ámbito, incluidos, sin ser los únicos, el hogar y el lugar de trabajo. (Jewkes, Sen, \& García, 2002, p. 149) (traducción libre)

Las diversas manifestaciones de violencia sexual, incluyendo el acoso sexual, son situaciones que generan manifiestas vulneraciones a los derechos humanos de las personas, en especial de las poblaciones que histórica y culturalmente son las víctimas de estas conductas. Aunque ha tomado tiempo, esfuerzo y mucha sangre comprenderlo, los Estados han ido aceptando la necesidad de realizar todas las medidas posibles para detener y disminuir las situaciones que permiten y apañan la violencia sexual en las sociedades. Esto no es solo producto de iniciativas estatales aisladas, sino que se basa en una serie de obligaciones provenientes de marcos regula- 
torios internacionales, así como de esfuerzos sumados desde diversas organizaciones a nivel mundial y regional que apuestan por visibilizar la violencia sexual en todas sus manifestaciones para generar cambios normativos que permitan un marco de protección a las víctimas y una garantía de sanción a los agresores. En este lado del mundo, los Estados americanos que son parte de la Convención Americana sobre Derechos Humanos, entre los que se encuentra el Perú, tienen obligaciones internacionales específicas y desarrolladas sobre el tema. Entre estas obligaciones o deberes se encuentra el de respetar y garantizar todos los derechos ${ }^{[1]}$.

Cuando nos referimos al deber de «garantizar» estamos hablando de que los Estados tendrán que realizar las acciones necesarias para procurar el libre y pleno ejercicio de los derechos reconocidos en la Convención a toda persona sujeta a su jurisdicción. Esta obligación implica el deber de los Estados Partes de organizar todo el aparato gubernamental y, en general, todas las estructuras a través de las cuales se manifiesta el ejercicio del poder público, de manera tal que sean capaces de asegurar jurídicamente el libre y pleno ejercicio de los derechos humanos. Como consecuencia de esta obligación, los Estados deben prevenir, investigar y sancionar toda violación de los derechos reconocidos por la Convención y procurar, además, el restablecimiento, si es posible, del derecho conculcado y, en su caso, la reparación de los daños producidos por la violación de los derechos humanos (Corte IDH, Caso Godinez Cruz vs. Honduras, 1989).
Esto significa, entonces, que los Estados deben generar las normas necesarias, las políticas públicas adecuadas y crear los organismos o instituciones suficientes para que la protección de los derechos sea real y efectiva, actuando desde diversos espacios y sectores con miras a lograr la erradicación de la violencia sexual. En relación con la obligación de investigar y el desempeño de los órganos jurisdiccionales que aplican las normas al interior del país, la Corte Interamericana de Derechos Humanos (Corte IDH) ha insistido que esta es una obligación de medios, no de resultados (Caso Baldeón García vs. Perú, 2006) [2]. Lo anterior significa que la investigación no puede ser emprendida como «una simple formalidad condenada de antemano a ser infructuosa» (Corte IDH, Caso Ximenes Lopes vs. Brazil, 2006) ${ }^{[3]}$. Por el contrario, cada acto estatal que conforma el proceso investigativo, así como la investigación en su totalidad, debe estar orientado hacia una finalidad específica, la determinación de la verdad y la investigación, persecución, captura, enjuiciamiento, y en su caso, la sanción de los responsables de los hechos (Corte IDH, Caso Cantoral Huamaní y García Santa Cruz vs. Perú, 2007).

De esta manera, la obligación de investigar se vuelve una herramienta importante en la cadena de acciones que un Estado debe promover y realizar con miras a combatir el problema de la violencia sexual, lo que implica que la investigación en los procesos penales relacionados a los delitos relacionados a la violencia sexual, como el acoso sexual, deben estar revestidos de estas garantías que permitan una

[1] Las Obligación de Respetar y Garantizar los derechos y libertades fundamentales se encuentran reconocidas en el artículo 1.1. de la Convención Americana sobre derechos humanos.

[2] La Corte Interamericana de Derechos Humanos en ese mismo sentido se ha pronunciado en la sentencia del Caso Velásquez Rodríguez vs. Honduras, 1988, párr. 177.

[3] La Corte Interamericana de Derechos Humanos en ese mismo sentido se ha pronunciado en las siguientes sentencias: Caso Velásquez Rodríguez vs. Honduras, 1988, párr. 177; Caso Masacres en Ituango vs. Colombia, 2006, párr. 296; Caso del Penal Miguel Castro Castro vs. Perú, 2006, párr. 255. 
investigación diligente y una sanción adecuada y oportuna para los agresores.

En opinión de la Corte IDH, es importante que las investigaciones (en especial las que tienen que ver con delitos de violencia sexual) eviten la revictimización, es decir, que durante el trámite de las denuncias se evite citar a la victima de manera que pueda re experimentar por medio de su relato los hechos que son materia de denuncia. (Caso Rosendo Cantú y otra vs. México, 2010) Esto significa que, al realizar la investigación y en el proceso de juzgamiento, las autoridades apliquen los protocolos adecuados y utilicen las mejores herramientas para que el testimonio de una víctima sea tomado por una única vez, evitando así que la víctima deba revivir una y otra vez los hechos que vulneran sus derechos y que le generaron daños.

En el caso peruano, la creación en el 2016 de la «Guía de procedimiento de entrevista única a víctimas en el marco de la Ley N. 030364 para prevenir, sancionar y erradicar la violencia contra las mujeres y los integrantes del grupo familiar; $y$, a niños y adolescentes varones víctimas de violencia» ${ }^{[4]}$ del Ministerio Público es un avance considerable que debe ir mejorando y reforzándose para su aplicación a la totalidad de casos de violencia sexual. En esa misma línea, en el 2019 se ha emitido el «Protocolo de Entrevista Única para niñas, niños y adolescentes en Cámara Gesell»»[5] por parte del Poder Judicial, apuntando a reforzar las garantías para la toma de declaración de víctimas mediante el mecanismo de la Cámara Gesell.

De igual manera, resulta importante tener en cuenta que una persona víctima de violencia sexual puede mantener reserva de su identidad, siendo asignada con una clave para su protección durante la investigación y judicialización ${ }^{[6]}$. Otro avance importante se refiere al Acuerdo Plenario N. ${ }^{\circ}$ 1-2011/CJ-116 que señala que el testimonio obtenido por la víctima en casos de delitos contra la libertad sexual (incluyendo el acoso sexual) se considerará como prueba anticipada, evitando que se le requiera relatar nuevamente lo sucedido en diversos espacios y frente a diferentes autoridades.

Finalmente, con respecto a lo mencionado, la Corte IDH ha afirmado que en una investigación penal por violencia sexual es necesario que: i) la declaración de la víctima se realice en un ambiente cómodo y seguro, que le brinde privacidad y confianza; ii) la declaración de la víctima se registre de forma tal que se evite o limite la necesidad de su repetición; iii) se brinde atención médica, sanitaria y psicológica a la víctima, tanto de emergencia como de forma continuada si así se requiere, mediante un protocolo de atención cuyo objetivo sea reducir las consecuencias de la violación; iv) se realice inmediatamente un examen médico y psicológico completo y detallado por personal idóneo y capacitado, en lo posible del sexo que la víctima indique, ofreciéndole que sea acompañada por alguien de su confianza si así lo desea; v) se documenten y coordinen los actos investigativos y se maneje diligentemente la prueba, tomando muestras suficientes, realizando estudios para determinar la posible autoría del hecho, asegurando otras pruebas como la ropa de la víctima, investigando de forma inmediata el lugar de los hechos y garantizando la correcta cadena de custodia, y vi) se brinde acceso a asistencia jurídica gratuita a la víctima durante todas las etapas del proceso (Caso Fernández Ortega y otros vs. México, 2010).

[4] Documento disponible en: https://www.mpfn.gob.pe/Docs/0/files/guia_03.pdf

[5] Protocolo recaído en al R.A. N. ${ }^{\circ}$ 277-2019-CE-PJ. Disponible en: http://www.gacetajuridica.com.pe/boletinnvnet/ar-web/Protocolo-C\%C3\%A1mara-Gesell.pdf

[6] Así lo señala la Ley $\mathrm{N}{ }^{\circ} 30364$ «Ley para prevenir, sancionar y erradicar la violencia contra las mujeres y los integrantes del grupo familiar» y su respectivo reglamento. 
En ese marco de obligaciones internacionales en derechos humanos, el legislador peruano ha cumplido con este deber al tipificar las conductas que plasman la violencia sexual a través del Código Penal, en especial el acoso sexual. Se cumple también, de esta manera, con una obligación internacional derivada del artículo 2 de la Convención Interamericana para Prevenir, Sancionar y Erradicar la violencia contra la mujer (Convención Belém do Pará) que señala:

\section{Artículo 2}

Se entenderá que violencia contra la mujer incluye la violencia física, sexual y psicológica:

a. que tenga lugar dentro de la familia o unidad doméstica o en cualquier otra relación interpersonal, ya sea que el agresor comparta o haya compartido el mismo domicilio que la mujer, y que comprende, entre otros, violación, maltrato y abuso sexual;

b. que tenga lugar en la comunidad y sea perpetrada por cualquier persona y que comprende, entre otros, violación, abuso sexual, tortura, trata de personas, prostitución forzada, secuestro y acoso sexual en el lugar de trabajo, así como en instituciones educativas, establecimientos de salud o cualquier otro lugar, y

c. que sea perpetrada o tolerada por el Estado o sus agentes, donde quiera que ocurra.

Como se puede ver, el acoso sexual es una conducta manifiesta de violencia sexual, reconocida como tal por los instrumentos jurídicos internacionales que vinculan al Perú, y por las mismas normas internas que han acogido esta premisa y la vienen implementando con éxito relativo en los diversos aspectos relacionados.

\section{ELEMENTOS DEL DELITO DE ACOSO SE- XUAL TIPIFICADO EN EL ARTÍCULO 176-B DEL CÓDIGO PENAL}

El artículo 176-B sobre acoso sexual señala:

El que, de cualquier forma, vigila, persigue, hostiga, asedia o busca establecer contacto o cercanía con una persona, sin el consen- timiento de esta, para llevar a cabo actos de connotación sexual, será reprimido con pena privativa de la libertad no menor de tres ni mayor de cinco años e inhabilitación, según corresponda, conforme a los incisos $5,9,10$ y 11 del artículo 36 .

Igual pena se aplica a quien realiza la misma conducta valiéndose del uso de cualquier tecnología de la información o de la comunicación.

La pena privativa de la libertad será no menor de cuatro ni mayor de ocho años e inhabilitación, según corresponda, conforme a los incisos 5, 9, 10 y 11 del artículo 36, si concurre alguna de las circunstancias agravantes:

1. La víctima es persona adulta mayor, se encuentra en estado de gestación o es persona con discapacidad.

2. La víctima y el agente tienen o han tenido una relación de pareja, son o han sido convivientes o cónyuges, tienen vínculo parental hasta el cuarto grado de consanguinidad o segundo de afinidad

3. La víctima habita en el mismo domicilio que el agente o comparten espacios comunes de una misma propiedad.

4. La víctima se encuentra en condición de dependencia o subordinación con respecto al agente.

5. La conducta se lleva a cabo en el marco de una relación laboral, educativa o formativa de la víctima.

6. La víctima tiene entre catorce y menos de dieciocho años. (Código Penal, 1991)

Como podemos ver, el tipo de la norma tiene los siguientes elementos constitutivos centrales que deben ser tomados en cuenta:

a) Sujeto activo: «El que».

b) Conducta: «vigila, persigue, hostiga, asedia o busca establecer contacto o cercanía con una persona».

c) Sujeto pasivo: «una persona».

d) Elemento subjetivo: «sin consentimiento de esta». 
e) Elemento objetivo: «Actos de connotación sexual».

Estos elementos constitutivos del tipo merecen un análisis especial cuando consideramos las diversas situaciones y conductas que pueden subsumirse en el tipo y ser sancionadas por esta norma.

\subsection{Sujeto activo del delito de acoso sexual}

Cuando la norma penal señala el delito de acoso sexual como la conducta realizada por «el que» vigila, persigue, hostiga, asedia o busca establecer contacto con una persona no podemos ignorar la generalidad del sujeto activo que realiza la conducta y que será sancionado. Este sujeto activo se refiere, precisamente, a cualquier persona que pueda cometer dichas conductas. Esto implica que, la generalidad que mencionamos tiene una finalidad y es deliberada, cosa que consideramos positiva comprendiendo que los diversos contextos y situaciones nos demuestran que el acoso sexual trasciende los estereotipos y va más allá de los casos más comunes.

Nos referimos a que, generalmente, se asume que la única persona capaz de cometer una conducta de acoso sexual es un hombre y que la norma no está dirigida a otras personas, considerando que no hay más posibilidades de sujeto activo. A pesar de esa creencia común, basada en estereotipos de género con referencia a la sexualidad masculina y a la supuesta impulsividad «incontrolable» de los deseos masculinos, el tipo penal no especifica que el sujeto activo deba ser un hombre, ni da ningún tipo de restricción o indicación sobre la identidad. En ese sentido, el sujeto pasivo podría ser cualquier persona, sin mayor restricción referida al sexo o género de la persona que realiza la conducta.

De esa manera, aunque no se corresponda con lo creído comúnmente, el delito de acoso sexual no es un delito especial ni se restringe para aplicarse únicamente a los hombres. La sanción puede imponerse a cualquier persona que comete las acciones señaladas contra otra persona. Consideramos apropiada esta formulación ya que implantar una restricción el sujeto activo solo reforzaría el estereotipo respecto de la masculinidad y haría que el tipo penal sea inaplicable para una serie de conductas que constituyen acoso sexual y deberían ser sancionadas.

\subsection{Las diversas conductas comprendidas en el delito de acoso sexual}

Otro elemento es el referente a la conducta que, de cualquier forma, realiza una persona que vigila, persigue, hostiga, asedia o busca establecer contacto o cercanía con otra persona. El listado de conductas no es taxativo, incluso señala que las conductas pueden realizarse «de cualquier forma» lo que genera una venta de oportunidad para incluir conductas que generen situaciones de acoso sexual y que no estén previstas de manera expresa en el listado específico.

A pesar de la intención de protección con la que pueda haber sido creado este tipo penal, se debe considerar que en el Derecho Penal (y todo tipo de disposición sancionatoria o restrictiva de derechos) se sigue el principio de legalidad considerando que las conductas sancionadas deben estar de manera expresa y taxativa, teniendo en cuenta, además, la prohibición del uso de analogías en el derecho sancionatorio.

Al respecto, la propia Corte Interamericana en el caso Norín Catrimán y otros vs. Chile ha señalado que:

La elaboración correcta de los tipos penales deberá cuidar siempre definiciones claras de las conductas incriminadas, que fijen sus elementos objetivos y subjetivos de modo que permita deslindarlas de comportamientos no punibles o de otras conductas ilícitas sancionables con medidas no penales. Es necesario que el ámbito de aplicación de cada uno de los tipos esté delimitado de la manera más clara y nítida 
que sea posible, en forma expresa, precisa, taxativa y previa (párr. 162) ${ }^{[7]}$.

Debido a lo mencionado, se debe aplicar el tipo de manera cuidadosa por los jueces penales con la finalidad de no desvirtuar la finalidad misma de la existencia de un delito de acoso sexual, pero sin que esto impida que se sancione, respetando los límites del debido proceso y las garantías judiciales pertinentes. Esta preocupación fue abordada por la Corte en el caso Pollo Rivera vs. Perú (2016) al analizar situaciones donde las aplicaciones de un tipo penal abierto implicaron violaciones a los derechos humanos de la persona procesada:

La Corte también ha resaltado que corresponde al juez, al momento de la aplicación de la ley penal, atenerse estrictamente a lo dispuesto por ésta [sic] y observar la mayor rigurosidad en la adecuación de la conducta de la persona incriminada al tipo penal, de forma tal que no incurra en la penalización de actos no punibles en el ordenamiento jurídico, o sea, que no proceda a una integración analógica (párr. 221).

Este aspecto se irá completando y entendiendo de mejor manera conforme se vayan judicializando diversos casos y se vaya aplicando el tipo penal a contextos reales y situaciones variadas.

Es interesante resaltar dos aspectos fundamentales relacionados a las conductas comprendidas como acoso sexual por el Código Penal. Por un lado, el acoso sexual no ha sido comprendido como una conducta que debe ser necesariamente reiterada, repetida o sostenida en el tiempo, esto quiere decir que no existe en la norma un requisito o elemento de frecuencia para que se configure el acoso sexual hacia una persona. En ese sentido, incluso una acción o conducta aislada a nivel temporal es considerada como un acto de acoso sexual y, por lo tanto, debe ser sancionada. Esta forma de concebir el acoso sexual resulta importante al tomar en cuenta que, ya que tampoco se requiere que haya un vinculo previo entre las personas involucradas, no tendría sentido requerir un elemento de reiterancia en la conducta que se mantenga en el tiempo.

Por otro lado, el tipo penal señala de manera específica que se aplica igual pena a quien realiza la conducta valiéndose del uso de cualquier tecnología de la información o de la comunicación. Esta aclaración introducida en el texto de la norma es una forma útil de plasmar un contexto especifico que actualmente es uno de los mecanismos más utilizados para el acoso sexual. La falta de restricciones, controles o filtros en el uso de mensajería instantánea, redes sociales, entre otras, genera que sean un mecanismo ideal para poder facilitar las conductas de acoso sexual, que incluso permite el anonimato de la persona agresora $y$, en consecuencia, dificulta la sanción de este.

\subsection{Sujeto pasivo del delito de acoso sexual}

Así como señalábamos en el literal a) de este apartado, el tipo penal no ha señalado restricción alguna con respecto a la persona víctima del acoso sexual. Esto quiere decir que, a pesar de que mayoritariamente sean las mujeres quienes son agredidas con estas conductas, ser víctima de acoso sexual no es exclusivo de las mujeres.

Es innegable que la cantidad de mujeres que sufren acoso sexual en el Perú es abrumadora y refleja una realidad cargada de violencia basada en género y de discriminación que nos interpela cada día. Según Datum Internacional (2018), el Perú se ubica en el segundo lugar en América Latina en porcentaje de casos de acoso sexual con $41 \%$ de personas que han sufrido en algún momento de conductas percibidas como acoso sexual.

[7] La Corte Interamericana de Derechos Humano en ese mismo sentido se ha pronunciado en las siguientes sentencias: Caso Castillo Petruzzi otros vs. Perú, 1999, párr. 121; Caso Fermín Ramirez vs. Guatemala., 2005, párr. 90. 
Figura 1

\section{ACOSO SEXUAL}

En el último año, ¿diría Ud. que ha sufrido en algún momento de acoso sexual?

\section{¿ूatum}

\begin{tabular}{|c|c|c|c|c|}
\hline PAÍS & Trabajo & $\begin{array}{c}\text { Centro de } \\
\text { estudios }\end{array}$ & $\begin{array}{c}\text { Algún } \\
\text { ámbito } \\
\text { social }\end{array}$ & $\begin{array}{c}\text { Otro } \\
\text { lugar }\end{array}$ \\
\hline MÉXICO & $15 \%$ & $7 \%$ & $34 \%$ & $27 \%$ \\
\hline PERÚ & $14 \%$ & $4 \%$ & $23 \%$ & $20 \%$ \\
\hline CHILE & $9 \%$ & $2 \%$ & $23 \%$ & $30 \%$ \\
\hline PANAMÁ & $13 \%$ & $5 \%$ & $23 \%$ & $21 \%$ \\
\hline ARGENTINA & $7 \%$ & $3 \%$ & $20 \%$ & $22 \%$ \\
\hline BRASIL & $7 \%$ & $1 \%$ & $13 \%$ & $11 \%$ \\
\hline ECUADOR & $5 \%$ & $4 \%$ & $15 \%$ & $17 \%$ \\
\hline ESTADOSUNIDOS & $10 \%$ & $4 \%$ & $15 \%$ & $4 \%$ \\
\hline COLOMBIA & $4 \%$ & $3 \%$ & $15 \%$ & $9 \%$ \\
\hline CANADA & $6 \%$ & $3 \%$ & $13 \%$ & $3 \%$ \\
\hline TOTALAMÉRICA & $9 \%$ & $4 \%$ & $18 \%$ & $17 \%$ \\
\hline
\end{tabular}
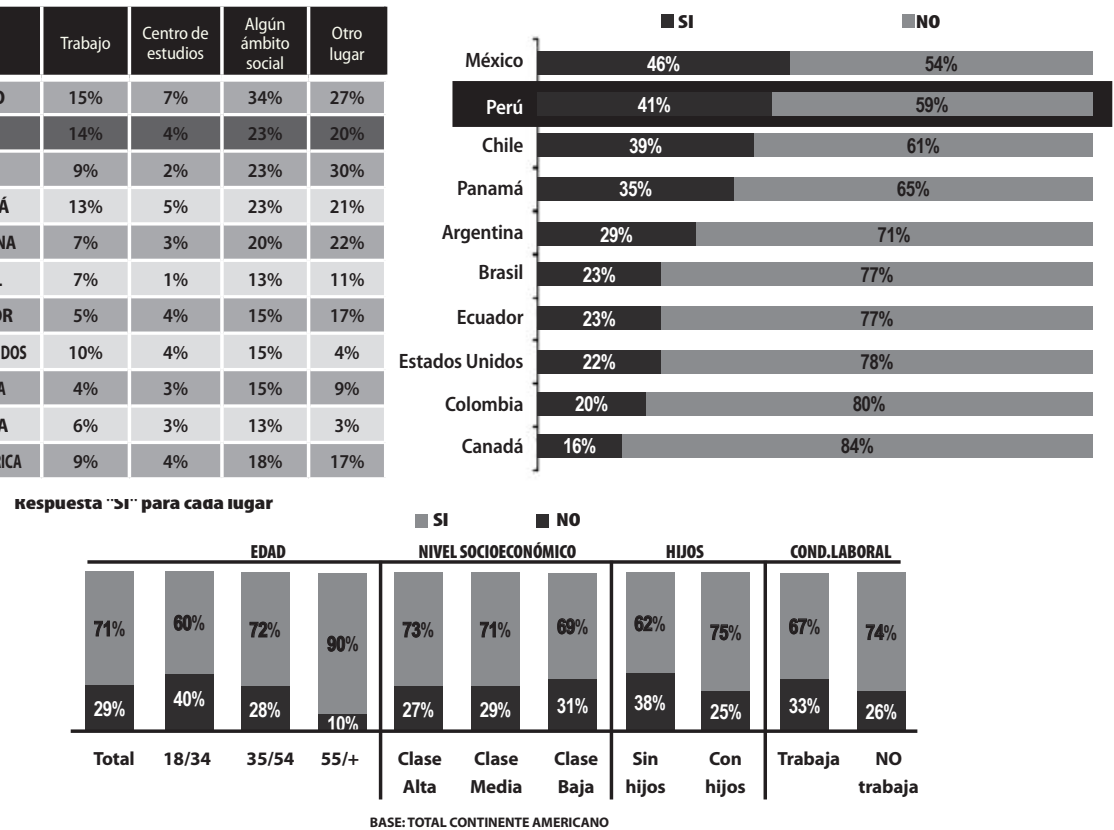

A pesar de esto, no podemos dejar de lado que existen personas que también sufren las mismas agresiones debido a características como su orientación sexual e identidad de género. Las personas con características diversas no normativas relacionadas a su identidad u orientación sexual sufren de constantes situaciones de violencia física, psicológica y sexual. La CIDH en uno de sus Informes Temáticos sobre la Violencia contra las personas LGBT ha dado un diagnóstico de la región andina que refleja la generalidad de la situación, pero también la poca información para medir el fenómeno de la violencia contra este grupo en situación de vulnerabilidad:

En el mes de diciembre de 2014, la CIDH publicó las conclusiones de su Registro de Violencia contra personas LGBT en América, una herramienta utilizada para conocer y visibilizar los alarmantes altos niveles de violencia que experimentan las personas
LGBT en la región. Este Registro arrojó que ocurrieron al menos 770 actos de violencia contra personas LGBT en un período de quince meses (desde enero de 2013 hasta marzo de 2014) en 25 Estados Miembros de la OEA (Argentina, Barbados, Belice, Bolivia, Brasil, Canadá, Chile, Colombia, Cuba, Ecuador, Estados Unidos, El Salvador, Guatemala, Guyana, Haití, Honduras, Jamaica, México, Nicaragua, Panamá, Paraguay, Perú, República Dominicana, Uruguay y Venezuela). Sin embargo, al momento de documentar estas estadísticas, la Comisión notó que la falta de información respecto de actos de violencia en otros países de América durante dicho período de tiempo no constituye una señal de que en esos países no hayan ocurrido actos de violencia. Es altamente probable que asesinatos y otros actos de violencia contra personas LGBT hayan ocurrido en esos países, pero que dicha violencia no haya sido denunciada 
oficialmente ni reportada por los medios de comunicación (CIDH, Comunicado de Prensa N. $\left.{ }^{\circ} 153 \mathrm{~A} / 14,2014\right)$.

Una de las muchas formas de violencia con la que las personas LGBT se ven obligadas a lidiar es, precisamente, el acoso sexual. Este tipo de agresiones tienen como una de sus principales fuentes al machismo violento con el que (sobre) vivimos. Es este tipo de concepción de las relaciones entre personas que lleva a muchos hombres a considerar que el acoso sexual a personas con identidad u orientación diversa es una forma de «reafirmar» su masculinidad. De esta forma, feminizar, agredir y cosificar a las personas es visto, de alguna manera, como una demostración de poder que se impone sobre los demás, considerándolos como seres inferiores que «merecen» esas agresiones por salirse de los patrones de la supuesta normalidad.

Son los hombres gais quienes se vuelven uno de los blancos preferidos de los acosadores cuando se trata de feminizar para intimidar y burlarse, generar mofa y escarnio, usando características de la expresión de género de estas personas como causa suficiente para ser agredidas y sometidas a ataques inmerecidos. Como se puede ver, las características de una persona que son utilizadas en estos casos para «elegir» a la víctima de las agresiones y el acoso sexual son, precisamente, las características protegidas por el derecho bajo los estándares del derecho a la igualdad y no discriminación, entendido también como principio fundamental del ordenamiento jurídico y del Estado.

Los ataques homofóbicos y el acoso sexual, en especial el que se da contra hombres gais, tienen fundamento en la idea de «feminizar» para hacer vulnerable a la otra persona y, por lo tanto, sentir que se tiene el derecho de cosificar a las personas y hacerlas objeto de sus agresiones. Si bien, como vimos, la mayoría de los casos de acoso sexual se dan entre hombre heterosexual - mujer, los casos de acoso sexual homofóbico tienen un componente extra: la finalidad de burlarse, hacer escarnio y producir miedo, reafirmando su supuesta masculinidad a costa de la otra persona, hacer temer al que es visto como menos hombre por ser gay o tener una expresión de género que no encaja en los parámetros de masculinidad «normales» para la sociedad peruana.

Entonces, es importante tener en claro que la identidad de género, la orientación sexual y la expresión de género son causales prohibidas de discriminación como ya se ha establecido de manera clara en la jurisprudencia de la Corte IDH (Caso Atala Riffo y niñas vs Chile, Duque vs. Colombia, Flor Freire vs. Ecuador y Rojas Marín y otra vs Perú, así como la Opinión Consultiva 24/17) y en la jurisprudencia del Tribunal Constitucional peruano (uno de los más recientes es el caso Romero Saldarriaga).

Considerando que son causales prohibidas de discriminación, correspondería entender que en el caso de acoso sexual homofóbico se debe aplicar el agravante señalado en el artículo 46.2.d) del Código Penal vigente ${ }^{[8]}$ que señala como agravante que el delito se ejecute bajo móviles de intolerancia o discriminación por características tales como la orientación sexual, identidad de género, entre otras.

\subsection{Elemento subjetivo: «sin consentimiento de esta»}

Este elemento presenta una dificultad especial debido a la normalización de la violencia que ya mencionábamos antes que, junto con

[8] «2. Constituyen circunstancias agravantes, siempre que no estén previstas específicamente para sancionar el delito y no sean elementos constitutivos del hecho punible, las siguientes:

d) Ejecutar el delito bajo móviles de intolerancia o discriminación, tales como el origen, raza, religión, sexo, orientación sexual, identidad de género, factor genético, filiación, edad, discapacidad, idioma, identidad étnica y cultural, indumentaria, opinión, condición económica, o de cualquier otra índole». 
las ideas machistas que pululan impunemente en los discursos de las peruanas y peruanos, generan una zona gris que muchas veces impide que incluso las mismas víctimas reconozcan que están sufriendo acoso.

Ante esto queremos utilizar el concepto más claro, sencillo y básico de «consentimiento», con la finalidad de que sea de fácil comprensión para todas las personas. En sencillo, el consentimiento implica que la conducta es a) buscada o solicitada de manera expresa y directa por la persona que es objetivo de la acción (manifestación o expresión de voluntad) o b) recibida de manera verdaderamente consciente y aceptada voluntariamente.

En ese sentido, cuando hablamos de acoso sexual se requiere que la conducta haya sido o espontánea o planificada únicamente por el agresor, entendiendo que la víctima de acoso sexual no ha solicitado de manera expresa y especifica dicha conducta, ni que, luego de producirse, la acepta de manera voluntaria y completamente libre.

Ante esto es necesario hacer una atingencia, muchas veces el acoso sexual se presume consentido cuando está disfrazado de «galantería» o «coqueteo», de esta manera, la mayoría de casos se da entre personas que no se conocen y que únicamente cruzan sus caminos en las calles de la ciudad, bajo la premisa de que está «permitido» realizar comentarios, sonidos, gestos, muecas, acercamientos o tocamientos cuando se trata de un supuesto halago o el popular «piropo».

Es esta visión de las cosas, la que lleva a mucha gente a no reconocer que estas conductas son meramente una forma de acoso sexual, tanto es así que las mismas víctimas muchas veces no son conscientes de la gravedad de la conducta y la dejan pasar por considerarla una forma «normal» en la que se expresan la mayoría de hombres.

Debido a todo esto, el acoso sexual ha sido una conducta invisibilizada y socialmente aceptada, permitiendo que los niveles de violencia aumenten cada vez más, llegando a grados incontrolables de violencia sexual contra mujeres y demás personas que son mantenidas en situación de vulnerabilidad, tal como señalábamos, incluyendo a las personas LGTB como población continuamente afectada.

Es más, el imaginario popular hace pensar incluso que uno de estos «piropos» es algo deseable o que es proporcional a la belleza de la mujer, por lo que, en lugar de ser una conducta reprochable, se convierte en una situación que debe ser hasta agradecida por la víctima. En el caso específico de la población LGTB, se toleran este tipo conductas por considerarlas «bromas» aceptadas. Incluso cuando se dan este tipo de conductas en público, las justificaciones casi siempre incluyen «no soy homofóbico, pero....», generalizando que el acoso sexual se use comúnmente para hacer escarnio de las personas LGTB sin que esto sea visto como un delito. De esta forma, el consentimiento se ve como un elemento que ni siquiera en esos casos es requerido, ni tomado en cuenta, considerando a la persona que recibe dichas conductas como incapaz de manifestar su oposición, desagrado y sin la capacidad de reclamar de alguna manera para que esa conducta se detenga.

\subsection{Elemento objetivo: «Actos de connota- ción sexual»}

Si bien ya hemos visto las diversas conductas y la amplitud del tipo para regularlas, es necesario ahora comprender que estas conductas deben estar revestidas de una connotación sexual que diferencia al acoso sexual de otros tipos penales. En ese sentido, la connotación sexual no ha sido definida en el tipo penal, aunque consideramos que no es necesario que se haga de forma expresa y taxativa teniendo en cuenta que el caso a caso nos dará una visión más clara de lo que se entiende por «sexual».

Este apartado se podrá complementar con la jurisprudencia que se produzca al utilizar este tipo penal, por ahora creemos importante 
solo esbozar algunas ideas. En primer lugar, tendrá un claro sentido sexual toda conducta que sea relativa al acto sexual, las zonas del cuerpo relacionadas a lo sexual y/o erógeno y aquello relacionado a cómo manifiestan y ejercen su sexualidad las personas diversas en lo concerniente a la identidad de género, orientación sexual y expresión de género.

En ese sentido, situaciones de acoso que mencionen o tengan que ver con esos aspectos, cumplirán con el requisito de la connotación sexual, más allá del término específico que se use, basándonos en la intención que denotan y el sentido común de los términos que se utilizan. Sobre este aspecto en especial, queremos recalcar la necesidad de considerar a las imitaciones o representaciones exageradas y con intención de burla o escarnio de la población LGTB como una forma de conducta con connotación sexual que puede encajar en el delito de acoso sexual teniendo en cuenta que dichas conductas reflejan una forma de agresión basada en la orientación sexual o identidad de género percibida, considerando que la forma en que estas personas ejercen o manifiestan su sexualidad es motivo suficiente para ser merecedoras del agravio. Es necesario tener en cuenta que los actos de discriminación vienen muchas veces manifestados a través de actos de acoso sexual y otras formas de violencia sexual, por lo que resulta importante entender la connotación sexual de las conductas de una forma integral y no restrictiva, en especial cuando hablamos de esta población.

\section{IMPACTO EN EL GOCE DEL ESPACIO PÚ- BLICO Y DEMÁS DERECHOS AFECTADOS POR LA HOMOFOBIA, COMO EL DERECHO AL LIBRE DESARROLLO DE LA PERSONA- LIDAD Y EL DERECHO A LA IDENTIDAD}

El acoso sexual tiene múltiples efectos en las víctimas y en la sociedad, es un delito pluriofensivo que produce afectaciones en diversos bienes jurídicos de la víctima y, por ende, en sus derechos. Las vulneraciones generadas en las mujeres víctimas de acoso sexual, son ya conocidas por los muchos estudios que se vienen realizando con miras a disminuir la situación de violencia en la que vivimos las mujeres peruanas. A pesar de eso, es poco conocido el efecto del acoso sexual en la población LGTB que lo sufre a diario.

Los delitos cometidos por homofobia y transfobia tienen múltiples efectos en las victimas, incluyendo la vulneración de varios de sus derechos, más aún si se tiene en cuenta que la mayoría de estos delitos se producen en espacios públicos, lo que genera un impacto en el uso y goce igualitario para todas y todos los ciudadanos. Podemos encontrar entre los derechos más afectados el derecho a la igualdad y no discriminación al ser estas personas agredidas por su orientación sexual, identidad de género y/o expresión de género, características prohibidas de discriminación.

Al respecto la $\mathrm{CIDH}$ en un reciente informe temático y en un comunicado conjunto ha afirmado sobre la situación de la región que «la violencia contra las personas trans es el resultado de la combinación de diversos factores, entre ellos, el prejuicio social como un fenómeno social, la falta de reconocimiento de identidades de género diversas, la discriminación, exclusión, y violencia social en general» (CIDH, 2018).

De igual forma, estas agresiones producen vulneraciones al derecho a la libertad de tránsito al generar que las víctimas no puedan transitar libremente, restringiendo sus posibilidades de desplazamiento libre en comparación con las demás personas presentes en ese lugar. Esto último se relaciona también con el derecho al libre desarrollo y bienestar, ya que las agresiones generan una situación de malestar y angustia que no permiten a las personas desarrollar sus actividades cotidianas con normalidad y tranquilidad. De esa forma, y como consecuencia de lo anterior, se produce una afectación real al derecho a la libertad de expresión ya que la víctima ve alterado el nor- 
mal desarrollo de sus actividades y de su forma de ser, asimismo altera la manera en que se expresa en la realización de su vida diaria. En ese sentido, «interferir arbitrariamente en la expresión de los distintos atributos de la identidad puede implicar una vulneración a ese derecho» (Corte IDH, Opinión Consultiva OC 24/17, 2017).

De esta forma, expresarse y vivir en un espacio cargado de violencia no permite que la identidad de una persona se desarrolle libremente y se exprese en el espacio en el que se desenvuelve, afectando también el derecho a la identidad de la persona (STC. Exp. N. ${ }^{\circ}$ 06040-2015-PA/TC, 2016, párr. 17-18).

Las afectaciones mencionadas producen en las víctimas una situación de estrés emocional que tiene secuelas, generándoles temor de desplazarse libremente y ser agredidas. Todo lo anterior implica una vulneración a su derecho a la integridad psíquica que se produce como consecuencia de las agresiones discriminatorias que sufren. Por último, y en relación con la connotación de las agresiones, se podría hablar de afectaciones al derecho al honor y buena reputación al recibir agresiones verbales sobre su orientación sexual, identidad de género y expresión de género de forma pública y despectiva.

No se puede dejar de lado a las secuelas en aspectos diversos que hacen posible que las agresiones sufridas tengan efectos en aspectos de las víctimas que se vayan desarrollando en el tiempo lo que podría incluso impactar en derechos económicos, sociales y culturales como el acceso a la educación, salud y derechos laborales.

El listado de derechos vulnerados por las agresiones discriminatorias no es taxativo ni pretende serlo, considerando que el ser humano tiene múltiples facetas en el desarrollo de su vida y es posible que las agresiones sufridas tengan secuelas en aspectos de las víctimas que se vayan desarrollando en el tiempo.

\section{PENDIENTES Y RETOS}

Ahora bien, ¿la mera tipificación de este delito será suficiente?, creemos que no, pues el abordaje de la violencia de género merece una aproximación político criminal que combata tanto las manifestaciones del delito, como aquellas causas ancladas en patrones de discriminación estructural que han generado este tipo de conductas. Sin embargo, dado cuenta que el proceso de adopción de una política criminal requiere de normas que hagan material el acceso a la justicia de las personas, es necesario que el castigo de este crimen tenga necesariamente una perspectiva de género, que implique que la justicia no solo responda subsumiendo el tipo penal, sino cumpliendo una labor pedagógica desde la argumentación jurídica de este tipo de decisiones.

Como sociedad, tenemos un reto constante y una deuda pendiente con la comunidad LGTB de nuestro país. La violencia es una situación tan constante que se ha normalizado hasta considerarla parte de la interacción cotidiana de las personas, quedando invisibilizada. Parte importante del problema yace en la idea de que estas agresiones son «bromas», considerarlas divertidas de alguna manera y validarlas con risas que intentan justificar delitos y hacerlos pasar por «chacota», incluso a través de medios de comunicación masivo como programas cómicos que han hecho que el acoso sexual sea visto como parte del humor peruano, impidiendo que incluso las mismas víctimas sean conscientes de estos delitos y de las implicancias de estas conductas, así como de la necesidad de denuncia de estos actos.

Ahora bien, seguirá siendo constante la preocupación por la forma en cómo los jueces entenderán y aplicarán el tipo penal en situaciones donde se alegue a la declaración de la víctima como una prueba en el supuesto donde solo se tenga como único medio de prueba a la declaración de la agraviada/o. Veremos en ese momento si los jueces aplicarán el Acuerdo Plenario 02-2005/CJ-116 para con- 
siderar a esta como único criterio para incriminar a una persona.

Así mismo, podría surgir como posible situación que los denunciados puedan alegar la presencia de error de tipo, prohibición o el error culturalmente condicionado para sustraerse de la responsabilidad, asunto que podría resultar problemático al tener los jueces que determinar en qué medida el desconocimiento de una norma o la normalización de la conducta puede ser un argumento para excluir la responsabilidad penal.

Finalmente, más allá de los problemas o retos que pudieran surgir de la aplicación de este nuevo delito debemos reafirmar que el derecho penal no es el único camino para acabar con las situaciones de violencia y acoso, sino que debe complementarse con medidas desde diversos espacios como la educación con enfoque de género, que en conjunto sirvan para que poco a poco vayamos comprendiendo que agredir a las personas por características como su orientación sexual, identidad de género y expresión de género no está permitido, no es legal y no será aceptado nunca más.

No, tu «broma» no da risa, es un delito.

\section{REFERENCIAS}

Jewkes, R., Sen, P., \& García, C. (2002). Sexual Violence [Violencia sexual]. En: E. Krug, Dahlberg, Linda, Mercy, James, A. Zwi, \& R. Lozano, (Eds.) World report on violence and health, 147-182. Organización Mundial de la Salud, Ginebra, Suiza. Obtenido de https:// www.who.int/violence_injury_prevention/violence/global_campaign/en/chap6.pdf?ua=1

\section{REFERENCIAS JURÍDICAS}

CIDH. (20 de noviembre de 2018). En el día e la memoria trans, la CIDH llama a los Estados a proteger integralmente la vida de las personas trans y de género diverso. Obtenido de http://www.oas.org/es/cidh/prensa/comunicados/2018/247.asp
CIDH. (17 de diciembre de 2014). Comunicado de Prensa N. ${ }^{\circ} 153 \mathrm{~A} / 14$. Una mirada a la violencia contra personas LGBTI en América: un registro que documenta actos de violencia entre el 1 de enero de 2013 y el 31 de marzo de 2014.

Corte Interamericana de Derechos Humanos (Corte IDH). 2006. Caso Ximenes Lopes vs. Brazil, Sentencia del 4 de julio de 2006. Serie C. N. ${ }^{\circ}$ 149. párr. 148.

Corte Interamericana de Derechos Humanos (Corte IDH). Caso Baldeón García v. Perú. Fondo, Reparaciones y Costas. Sentencia del 6 de abril de 2006. Serie C. No.147. párr. 93.

Corte Interamericana de Derechos Humanos (Corte IDH). 2007. Caso Cantoral Huamaní y García Santa Cruz vs. Perú. Excepción Preliminar, Fondo, Reparaciones y Costas. Sentencia del 10 de julio de 2007. Serie C. N. ${ }^{\circ} 167$. párr. 131.

Corte Interamericana de Derechos Humanos (Corte IDH). 2010. Caso Fernández Ortega y otros vs. México. Excepción Preliminar, Fondo, Reparaciones y Costas. Sentencia del 30 de agosto de 2010. Serie C. N. ${ }^{\circ} 215$, párr. 194.

Corte Interamericana de Derechos Humanos (Corte IDH).1989. Caso Godinez Cruz vs. Honduras. Fondo. Sentencia del 20 de enero de 1989. Serie C. N. ${ }^{\circ}$ 5, párr. 175

Corte Interamericana de Derechos Humanos (Corte IDH). 2006. Caso Masacres en Ituango vs. Colombia. Sentencia del 1 de julio de 2006. Serie C. N. ${ }^{148}$, párr. 296.

Corte Interamericana de Derechos Humanos (Corte IDH). 2010. Caso Rosendo Cantú y otra vs. México. Excepción Preliminar, Fondo, Reparaciones y Costas. Sentencia del 31 de agosto de 2010. Serie C. N. ${ }^{\circ} 216$, párr. 180.

Corte Interamericana de Derechos Humanos (Corte IDH). 1988. Caso Velásquez Rodriguez vs. Honduras. Fondo. Sentencia del 29 de julio de 1988. Serie C. N. ${ }^{\circ}$ 04, párr. 177. 
Corte Interamericana de Derechos Humanos (Corte IDH). 1999. Caso Castillo Petruzzi otros vs. Perú. Fondo, Reparaciones y Costas. Sentencia del 30 de mayo de 1999. Serie C. N. ${ }^{\circ}$ 22, párr. 121.

Corte Interamericana de Derechos Humanos (Corte IDH). 2005. Caso Fermín Ramirez vs. Guatemala. Fondo, Reparaciones y Costas. Sentencia del 20 de junio de 2005. Serie C. N. ${ }^{\circ}$ 126, párr. 90.

Corte Interamericana de Derechos Humanos (Corte IDH). 2014. Caso Norín Catrimán y otros (Dirigentes, miembros y activistas del Pueblo Indígena Mapuche) vs. Chile. Fondo, Reparaciones y Costas. Sentencia del 24 de mayo de 2014. Serie C. N. ${ }^{\circ}$ 279, párr. 162.
Corte Interamericana de Derechos Humanos (Corte IDH). 2016. Caso Pollo Rivera y otros vs. Perú. Fondo, Reparaciones y Costas. Sentencia del 21 de octubre de 2016. Serie C. N. ${ }^{\circ} 319$, párr. 221.

Corte IDH. Opinión Consultiva OC 24/17 de 24 de noviembre de 2017 solicitada por la República de Costa Rica sobre Identidad de Género e lgualdad y no discriminación a parejas del mismo sexo, párr. 96.

Código Penal. (03 de abril de 1991). https:// Ipderecho.pe/codigo-penal-peruano-actualizado/

STC. Exp. N. ${ }^{\circ}$ 06040-2015-PA/TC, 2016, párr. 17-18. 